\title{
Adoption of Electronic Medical Record (EMR) System in Government Hospitals: A Case Study of Government Civil Hospital - Gandhinagar, Gujarat, India
}

\author{
Prof. Dr. Vasudev Modi
}

\begin{abstract}
Healthcare is one of India's largest sectors, in terms of revenue and employment. Indian healthcare is experiencing a new wave of opportunity. Providers are reinventing existing delivery models to bring healthcare closer to the patient. The Indian healthcare industry is growing at a tremendous pace owing to its strengthening coverage, services and increasing expenditure by public as well private players. During 2008-20, the market is expected to record a CAGR of 16.5 per cent. The total industry size is expected to touch US\$ 160 billion by 2017 and US $\$ 280$ billion by 2020. Rising income levels and a growing elderly population are all factors that are driving this growth. Healthcare worldwide is constantly undergoing changes due to new research findings, new medical technologies and new business models. These challenges are further compounded by the fact that healthcare is an information intensive field. The benefits of Information Technology (IT) can be effectively addressing the challenges faced by healthcare providers. Information Technology solutions in healthcare help provide enhanced care to patients while conforming to present and emerging standards and regulations and ensuring seamless integration within the various departments of the hospital. In context of this, researchers have conducted primary study on extensive use of technology-EMR in managing comprehensive records of each \& every patients in hospital. Along with this, researchers have focused on case study of implementation of EMR \& HMIS at Gandhinagar hospital located in Gujarat State, India \& identified its importance.
\end{abstract}

Keywords - Electronic Medical Record; Government hospital; HMIS; Information system

\section{INTRODUCTION}

Healthcare is one of India's largest sectors, in terms of revenue and employment, and the sector is expanding rapidly. The Indian healthcare industry is growing at a tremendous pace owing to its strengthening coverage, services and increasing expenditure by public as well private players. During 2008-20, the market is expected to record a CAGR of 16.5 per cent. The total industry size is expected to touch US\$ 160 billion by 2017 and US $\$ 280$ billion by 2020. (Source: IBEF Healthcare Sector Report).

Prof. (Dr.) Vasudev Modi, Professor, Department of Commerce, M. K. Bhavnagar University, Bhavnagar, Gujarat, India
Rising income levels and a growing elderly population are all factors that are driving this growth. In addition, changing demographics, disease profiles and the shift from chronic to lifestyle diseases in the country has led to increased spending on healthcare delivery.

\section{A. Healthcare, IT and EMR (Electronic Medical Records)}

In the past 25 years, information technology has revolutionized virtually every facet of our lives. In today's healthcare practices of all types and sizes, information is both a benefit and a challenge for every provider. New information about disease and treatment is saving lives, while a lack of effectively managed data can put this information at risk.

In current scenario the health care sectors are dependent upon software applications, as software applications provide the platform through which various medical functions are performed such as Image Processing, MRI scan, health care management and HIS etc. Innovative hospitals and healthcare providers are increasingly incorporating new software applications and fundamental part of the business strategy is to help, meet and beat expectations of patients and shareholders. Nation and Region Wide Electronic Health Records are being deployed in several countries around the world to enable sharing the care records within the organization and between different organizations. Healthcare industry providers are under pressure to integrate data across the entire continuum of care while building the patient loyalty.

\section{B. Concept of EMR}

Electronic Medical Record (EMR) or Electronic Health Record (EHR) by definition is a patient's medical record in an electronic format, accessible by computers on a network for the primary purpose of providing healthcare and health-related services. Medical records have evolved over time, earlier it was paper based charts in which the patient's medical records were maintained.

\section{LITERATURE REVIEW}

Many researchers have researched on several aspects related to maintaining EMR in healthcare organizations. Richard Hillestad et.al (2005) researched whether electronic medical record systems can transform Health Care and broadly examined the potential health and financial benefits of health 
information technology.

Rhonda J. Richards, Victor R. Prybutok and Sherry D. Ryan, (2012) presented a conceptual model that posits the strategic relationships between information technology, clinic operations and physicians and the subsequent outcomes to patients, physicians and clinics which can lead to competitive advantages in the healthcare environment. Douglas J. Ayers, Nir Menachemi, Zo Ramamonjiarivelo, Michael Matthews and Robert G. Brooks, (2009) examined the role of network effects defined as increased utility for users of a technology that occurs when adoption increases among other users. Kurt Stanberry, (2011), tried to analyze attempts in the USA and globally, to create new and improved methods used to manage patient health information: electronic medical records (EHRs).

Olivia F. Lee and Matthew L. Meuter (2010), David B. Meinert and Dane Peterson, (2009) and Tsipi Heart, Philip O'Reilly, David Sammon and John O'Donoghue, (2009) tried to address and explore the role of technology through the study of electronic health record system in delivering patientcentered services.

\section{RESEARCH METHODOLOGY}

\subsection{Research design}

Exploratory and Descriptive research design has been used..

\subsection{Objectives of Study}

1. To know the application of EMR system and its benefits in the healthcare sector.

2. To know how often hospital staff uses the electronic medical records system for certain tasks in everyday clinical work.

3. To study the hospital staff's perception towards utility and the use of EMR system for clinical tasks management in the hospital.

4. To measure the perceptions towards the performance of clinical tasks while using the EMR system.

5. To measure the satisfaction of clinical staff towards using EMR system.

\subsection{Data Collection}

Secondary Data: was collected from different research papers, case studies, journals and healthcare websites.

Primary Data: It was collected by approaching the medical and operational staff of Clinic / hospital. A structured questionnaire was prepared and personal interviews were conducted with 50 different respondents belongs to medical \& para-medical staff. Judgment sampling was used in selection of respondents. A government hospital that has implemented Health Management Information System for the purpose of keeping electronic records was identified and some information about their process of implementation and benefits was also gathered.

\section{HEALTH MANAGEMENT INFORMATION SYSTEM (HMIS) - EMR System: A CASE STUdy Of GOVERNMENT CiVIL HosPitAl, GANDHINAGAR}

\section{Overview}

The Government of Gujarat has identified quality health services and the efficiency of Government managed hospitals as key contributors for building trust and confidence for the general hospitals in the hearts of the citizen of the state. State of Gujarat is one of the largest state of India with population above 5 crore spreading all over 27 districts, having more than 18,618 villages and 242 towns. About $37.79 \%$ population of the state resides in urban areas. Health and Family Welfare Department (HFWD) looks after healthcare facilities and administers public health policies in the state and governs 27 district hospitals and 6 medical college associated hospitals.

\section{Issues and Challenges}

HMIS was conceptualized to alleviate following set of issues and challenges for the Health Department:

1. Earlier the government was getting the reports from each hospital at the end of the month which was the statistics for the month and the consolidation of the same was done in the next month and it was unknown on real time basis.

2. Also for the hospital administrators it was difficult or rather did not get the information of each department, resource scheduling, online patient clinical data, and patient's demographic details online.

3. Vital statistics is an integral part of the health information in HFWD. The health management system is composed of: a. Demography and vital events b. Health status - mortality, morbidity - disability. c. Health resources: facilities, beds, manpower d. Utilization of health services e. Financial statistics related to health, medical services and medical education

\section{Solution}

HMIS project was conceptualized by the department of health and family welfare to ensure quality health care by IT application in such a manner so has to provide standard clinical and diagnostic protocol tools, hospital management tools and integration of management information at the state level so as to ensure online review \& monitoring. This was aimed at management of vital patient records and analysis of the critical health related data so as to provide an updated planning and policy tool towards provision of quality health services. The HMIS is a web-enabled system, which practically supports any time-anywhere access by the users. However, the user access has been controlled through GSWAN and role-based access has been imposed in order to protect security of patient records.

\section{Strategy}

It selected TCS (Tata Consultancy Services) as an IT partner, who had required expertise and total solutions with ready-todeploy HMIS framework application earlier, therefore having proven record and experience about functional as well as technical know-how \& Identified SSG, Vadodara as computer teaching partner. And Gandhinagar Civil hospital selected as district hospital for pilot sites - users across different roles 
were interviewed, observations documented and Proof-ofConcept replayed to these users prior to their approving for roll-out to other hospitals. Setting up of Project Implementation Unit (PIU), to facilitate infrastructure required for smooth implementation of project. And a Central Help Desk was formed to provide online support for HMIS to the various sites of Gujarat.

\section{DATA ANALYSIS \& INTERPRETATION}

\subsection{General use of EMR and paper-based medical record}

(1) Never / Almost never

(2) Seldom

(3) About half of the occasions

(4) Most of the occasions

(5) Always / Almost always.

TABLE I

\begin{tabular}{|c|c|c|c|c|c|c|}
\hline Sr. No & Uses & (1) & (2) & (3) & (4) & (5) \\
\hline 1 & $\begin{array}{l}\text { How often do you use the paper-based medical record or } \\
\text { the chart summary as an Information source in your daily } \\
\text { clinical work? }\end{array}$ & & & & 23 & 27 \\
\hline 2 & $\begin{array}{l}\text { How often do you use the EMR as an information source } \\
\text { in your daily clinical work? }\end{array}$ & & & & 19 & 31 \\
\hline 3 & $\begin{array}{l}\text { How often do you use the EMR when transferring patient- } \\
\text { related information to other persons or instances (by } \\
\text { printouts or by electronic transmission) }\end{array}$ & & & & 24 & 26 \\
\hline
\end{tabular}

\subsection{Use of electronic medical records for clinical tasks in the hospital}

(1) Never / Almost never

(2) Seldom

(3) About half of the occasions

(4) Most of the occasions

(5) Always / Almost always

(A) Our EMR doesn't support this task

(B) This task does not apply to me

\section{TABLE II}

\begin{tabular}{|c|c|c|c|c|c|c|c|c|}
\hline Sr. No & Tasks & (1) & (2) & (3) & (4) & (5) & (A) & (B) \\
\hline 1 & Review the patients' problems & & & & 02 & 48 & & \\
\hline 2 & Seek out specific information from patient records & & & & 08 & 42 & & \\
\hline 3 & $\begin{array}{l}\text { Follow the results of a particular test for } \\
\text { investigation over time }\end{array}$ & & & 03 & 17 & 30 & & \\
\hline 4 & Obtain the results from new test or investigations & & 01 & 08 & 04 & 37 & & \\
\hline 5 & Enter daily notes & & & & 07 & 43 & & \\
\hline 6 & $\begin{array}{l}\text { Obtain information on investigation or treatment } \\
\text { procedures }\end{array}$ & 01 & & & 09 & 40 & & \\
\hline 7 & $\begin{array}{l}\text { Answer questions concerning general medical } \\
\text { knowledge (e.g. concerning treatment, Symptoms, } \\
\text { complications etc.) }\end{array}$ & & & & 10 & 40 & & \\
\hline 8 & $\begin{array}{l}\text { Produce data reviews for specific patient groups, } \\
\text { e.g. complication rate, diagnoses }\end{array}$ & & & & 10 & 40 & & \\
\hline 9 & Order clinical biochemical laboratory analyses & 01 & & 05 & 03 & 41 & & \\
\hline 10 & $\begin{array}{l}\text { Obtain the results from clinical \& biochemical } \\
\text { laboratory analyses }\end{array}$ & 05 & & 01 & 10 & 34 & & \\
\hline 11 & Order X-ray, ultrasound or CT investigations & & & 06 & 05 & 34 & & \\
\hline 12 & $\begin{array}{l}\text { Obtain the results from X-ray, ultrasound or CT } \\
\text { investigations }\end{array}$ & 05 & 01 & & 06 & 38 & & \\
\hline 13 & Order other supplementary investigations & & & 07 & 06 & 37 & & \\
\hline 14 & $\begin{array}{l}\text { Obtain the results from other supplementary } \\
\text { investigations }\end{array}$ & 05 & & 02 & 03 & 40 & & \\
\hline 15 & $\begin{array}{l}\text { Refer the patient to other departments or } \\
\text { specialists }\end{array}$ & 01 & 01 & 04 & 07 & 37 & & \\
\hline 16 & $\begin{array}{l}\begin{array}{l}\text { Order treatment directly } \\
\text { operations etc.) }\end{array} \\
\end{array}$ & & & & 07 & 43 & & \\
\hline 17 & Write prescriptions & & & 02 & 04 & 44 & & \\
\hline 18 & Write sick-leave notes & 01 & & 01 & 07 & 41 & & \\
\hline 19 & $\begin{array}{l}\text { Collect patient information for various medical } \\
\text { declarations }\end{array}$ & 01 & & & 05 & 44 & & \\
\hline 20 & $\begin{array}{l}\text { Give written individual information to patients, } \\
\text { e.g. about medications, disease status }\end{array}$ & 01 & 01 & 07 & 03 & 38 & & \\
\hline 21 & $\begin{array}{l}\text { Give written general medical information to } \\
\text { patients }\end{array}$ & 01 & 06 & 01 & 09 & 33 & & \\
\hline 22 & Collect patient info for discharge reports & 01 & & & 03 & 46 & & \\
\hline 23 & Check and sign typed dictations & 01 & & 02 & 02 & 45 & & \\
\hline 24 & $\begin{array}{l}\text { Register codes for diagnosis or performed } \\
\text { procedures }\end{array}$ & & & & 06 & 44 & & \\
\hline
\end{tabular}




\subsection{Ease of clinical work tasks when using the EMR}

(1) Significantly more difficult (2) More difficult slightly more difficult (4) No Change
(5) slightly easier (6) Easier (7) Significantly easier (8) don't know / Not Applicable ).

\begin{tabular}{|c|c|c|c|c|c|c|c|c|c|}
\hline Sr. No & Uses & (1) & (2) & (3) & (4) & (5) & (6) & (7) & $(8)$ \\
\hline 1 & To review the patients' problems has become & & & 01 & 01 & 02 & 25 & 21 & \\
\hline 2 & $\begin{array}{l}\text { To seek out specific information from patient records has } \\
\text { become }\end{array}$ & & & & & 02 & 33 & 15 & \\
\hline 3 & $\begin{array}{l}\text { To follow the results of a particular test or investigation } \\
\text { over time has become }\end{array}$ & & & & & 04 & 27 & 19 & \\
\hline 4 & $\begin{array}{l}\text { To obtain the results from new tests or investigations has } \\
\text { become }\end{array}$ & & & & & 02 & 24 & 24 & \\
\hline 5 & To enter daily notes has become & & & & & 03 & 30 & 17 & \\
\hline 6 & $\begin{array}{l}\text { To obtain information on investigation or treatment } \\
\text { procedures has become }\end{array}$ & & & & & 04 & 30 & 16 & \\
\hline 7 & $\begin{array}{l}\text { To answer questions concerning general medical } \\
\text { knowledge (e.g. concerning treatment, Symptoms, } \\
\text { complications etc.) has become }\end{array}$ & & & & 01 & 03 & 30 & 16 & \\
\hline 8 & $\begin{array}{l}\text { To produce data reviews for specific patient groups (e.g. } \\
\text { complication rate) has become }\end{array}$ & & & & 01 & 04 & 29 & 16 & \\
\hline 9 & $\begin{array}{l}\text { To order clinical biochemical laboratory analyses has } \\
\text { become }\end{array}$ & & & & & 02 & 29 & 19 & \\
\hline 10 & $\begin{array}{l}\text { To obtain the results from clinical biochemical laboratory } \\
\text { analyses has become }\end{array}$ & & & & & 03 & 21 & 26 & \\
\hline 11 & $\begin{array}{l}\text { To order X-ray, ultrasound or CT investigations has } \\
\text { become }\end{array}$ & & & & & 01 & 29 & 20 & \\
\hline 12 & $\begin{array}{l}\text { To obtain the results from X-ray, ultrasound or CT } \\
\text { investigations has become }\end{array}$ & & & & & 04 & 15 & 31 & \\
\hline 13 & To order other supplementary investigations has become & & & & 03 & 03 & 31 & 13 & \\
\hline 14 & $\begin{array}{l}\text { To obtain the results from other supplementary } \\
\text { investigations has become }\end{array}$ & & & & 03 & 03 & 23 & 21 & \\
\hline 15 & $\begin{array}{l}\text { To refer the patient to other departments or specialists } \\
\text { has become }\end{array}$ & & & & 02 & & 27 & 21 & \\
\hline 16 & $\begin{array}{l}\text { To order treatment directly (e.g. medicines, Operations } \\
\text { etc.) has become }\end{array}$ & & & & 02 & 02 & 28 & 18 & \\
\hline 17 & To write prescriptions has become & & & 02 & & 02 & 28 & 18 & \\
\hline 18 & To complete sick-leave forms has become & & & & 01 & 01 & 25 & 23 & \\
\hline 19 & $\begin{array}{l}\text { To collect patient information for various medical } \\
\text { declarations has become }\end{array}$ & & & & & 03 & 31 & 16 & \\
\hline 20 & $\begin{array}{l}\text { To give written individual information to patients, (e.g. } \\
\text { about medications, diseases' status) has become }\end{array}$ & & & & & 04 & 27 & 19 & \\
\hline 21 & $\begin{array}{l}\text { To give written general medical information to patients } \\
\text { has become }\end{array}$ & & & & & 05 & 28 & 17 & \\
\hline 22 & $\begin{array}{l}\text { To collect patient information for discharge reports has } \\
\text { become }\end{array}$ & & & & 01 & 05 & 18 & 26 & \\
\hline 23 & To check and sign typed dictations has become & & & & 01 & 02 & 25 & 22 & \\
\hline 24 & $\begin{array}{l}\text { The register codes for diagnosis or performed procedures } \\
\text { has become }\end{array}$ & & & 02 & 01 & 03 & 24 & 20 & \\
\hline
\end{tabular}

4.4 Satisfaction with the electronic medical record (EMR) system in your departments

\begin{tabular}{|c|c|c|c|c|c|c|}
\hline Sr. No & EMR aspects & (1) & (2) & (3) & (4) & (5) \\
\hline 1 & Content & & & & & \\
\hline $1 . \mathrm{a}$ & How often does the system provide the precise information you need? & & & 06 & 17 & 27 \\
\hline $1 . \mathrm{b}$ & How often does the information content meet your needs? & & & 02 & 19 & 29 \\
\hline $1 . c$ & How often does the system provide reports that seem to be just about exactly what you need? & 01 & 01 & 04 & 13 & 31 \\
\hline $1 . \mathrm{d}$ & How often does the system provide sufficient information? & & & 04 & 15 & 31 \\
\hline 2 & Accuracy & & & & & \\
\hline $2 . \mathrm{a}$ & How often is the system accurate? & 01 & 01 & 02 & 14 & 32 \\
\hline $2 . \mathrm{b}$ & How often are you satisfied with the accuracy of the system? & & 01 & 03 & 21 & 25 \\
\hline 3 & Format & & & & & \\
\hline $3 . \mathrm{a}$ & How often do you think the output is presented in a useful format? & & & 03 & 15 & 32 \\
\hline 3.b & How often is the information clear? & & & 03 & 14 & 33 \\
\hline 4 & Ease of Use & & & & & \\
\hline $4 . \mathrm{a}$ & How often is the system user-friendly? & & 01 & 03 & 14 & 32 \\
\hline $4 . \mathrm{b}$ & How often is the system easy to use? & & 01 & 03 & 18 & 28 \\
\hline 5 & Timeliness & & & & & \\
\hline $5 . \mathrm{a}$ & How often do you get the information you need in time? & & 01 & 02 & 14 & 33 \\
\hline $5 . \mathrm{b}$ & How often does the system provide up-to-date information? & & & 02 & 14 & 34 \\
\hline
\end{tabular}


As seen in above table-1 almost all the respondents have indicated that they use the EMR as an information source in their daily clinical work as well as for transferring patientrelated information to other persons (by printouts or by electronic transmission

\section{Interpretations: (Drawn from Table: $2 \&$ 3)}

1. $96 \%$ people are almost always using the EMR to review the patient's problems. Out of them it has been significantly easier to review patients' problems for $42 \%$ of people, easier for $42 \%$ of people, slightly easier for $4 \%$ of people, no change for $2 \%$ of people and has become slightly more difficult for $2 \%$ of people. So for more than $95 \%$ of people the task of reviewing problem has become easier than before.

2. $84 \%$ people are almost always using the EMR to seek out specific information from patients' records, where as $16 \%$ people use the EMR for most of the occasions. Out of them it has been significantly easier to seek out specific information from patients' records for $30 \%$ of people, easier for $66 \%$ of people and slightly easier for $4 \%$ of people. So for more than $96 \%$ of people to seek out the specific information from patients' records have become easier than before.

3. $60 \%$ people are almost always using the EMR to follow the results of a particular test or investigation over time, whereas 34\% people use the EMR for most of the occasions and $6 \%$ are using it for half of the time. For almost all the people, the task of following the result of a particular test or investigation over time has become easier than before.

4. $82 \%$ people use the EMR to obtain the result from new tests or investigation, and for almost all of them the task has become easier than before.

5. $86 \%$ people are using the EMR to enter daily notes; and for almost all $100 \%$ of people to enter a daily note has become easier than before.

6. $80 \%$ people are using the EMR to obtain information on investigation or treatment procedures and the task has become easier for almost all of them.

7. $80 \%$ people are using the EMR to answer questions concerning general medical knowledge and for $98 \%$ of people it has become easier with EMR.

8. $80 \%$ people are using the EMR to produce data reviews for specific patient groups and again for almost $98 \%$ of people to produce data reviews for specific patient groups have become easier with EMR.

9. $82 \%$ people are using the EMR to order clinical biochemical laboratory analyses and for all of them the task has become easier with EMR.

10. $68 \%$ people are almost always using the EMR to obtain the results from clinical biochemical laboratory analysis whereas $20 \%$ people use the EMR for most of the occasions, $2 \%$ use it half of the occasions \& for all of them to obtain the results from clinical biochemical laboratory analysis has become easier with EMR than before.

11. $88 \%$ people are using the EMR to order $\mathrm{x}$-ray, ultrasound or CT investigation and for all $100 \%$ of people to order $\mathrm{x}$ - ray, ultrasound or CT investigation has become easier with EMR than before.

12. $76 \%$ people are almost always using the EMR to obtain results from x-ray, ultrasound or CT investigation whereas $12 \%$ people use the EMR for most of the occasions, $2 \%$ use it seldom \& $10 \%$ use it never. Out of them it has been significantly easier to obtain the results from x-ray, ultrasound or CT investigation for $62 \%$ of people, easier for $30 \%$ of people \& slightly easier for $8 \%$ of people.

13. $74 \%$ people are almost always using the EMR to order other supplementary investigation whereas $12 \%$ people use the EMR for most of the occasions \& $14 \%$ use it half of the occasions. Out of them for around $94 \%$ of people to order other supplementary investigations have become easier with EMR than before.

14. $80 \%$ people are using the EMR to obtain the results from other supplementary investigations and for $94 \%$ of people tasks of obtaining the results from other supplementary investigation have become easier with EMR than before.

15. $74 \%$ people are almost always using the EMR to refer the patient to other departments or specialists whereas $14 \%$ people use the EMR for most of the occasions, $8 \%$ use it half of the occasions, $2 \%$ seldom \& $2 \%$ never use it for the same. Around $96 \%$ of people's tasks of referring the patients to other departments or specialists have become easier with EMR.

16. $86 \%$ people are almost always using the EMR to order treatment directly whereas $14 \%$ people use the EMR for most of the occasions. Out of them around $96 \%$ of people's tasks of ordering treatments directly have become easier with EMR.

17. $88 \%$ people are almost always using the EMR to write prescriptions, whereas $14 \%$ people use the EMR for most of the occasions \& $4 \%$ for half of the time for the same. Around $96 \%$ of peoples' tasks of writing prescriptions have become easier with EMR.

18. $82 \%$ people are almost always using the EMR to complete sick leave forms, whereas $14 \%$ people use the EMR for most of the occasions, $2 \%$ for half of the time \& $2 \%$ for never for the same. Around $98 \%$ of people feel easier to complete sick-leave forms with EMR.

19. $88 \%$ people are almost always using the EMR to collect patients' information for various medical declarations, whereas $10 \%$ people use the EMR for most of the occasions \& $2 \%$ never for the same. All the people feel easier to collect patient information for various medical declarations using EMR.

20. $76 \%$ people are almost always using the EMR to give written individual information to patients, whereas $6 \%$ people use the EMR for most of the occasions, $14 \%$ for half of the time, $2 \%$ seldom \& $2 \%$ of them never for the same. All the respondents feel easier to give written individual information to patients using EMR.

21. 66\% people are almost always using the EMR to give written general medical information to patients, whereas $18 \%$ people use the EMR for most of the occasions. Almost all find it easier to give written general medical information to patients using EMR. 
22. $92 \%$ people are using the EMR to collect patients' information for discharge reports, and $98 \%$ of people easily collect patients' information for discharge reports using EMR.

23. $90 \%$ people are using the EMR to check and sign typed dictations, and almost $98 \%$ of people easily check and sign typed dictations using EMR.

24. $88 \%$ people are almost always using the EMR to register codes for diagnosis for performed procedures, whereas $12 \%$ people use the EMR for most of the occasions for the same. Almost $90 \%$ of people easily register codes for diagnosis or performed procedures using EMR

\section{Interpretations: (Drawn from Table: 4)}

1. $54 \%$ people feel that system provides the precise information they need for almost all the times, $34 \%$ get it for most of the time $\& 12 \%$ get it for half of the time. Thus in most of the cases the precise information people need can be obtained by them using the EMR.

2. 58\% of people find that the information contents meet their needs for almost all the times, $38 \%$ get it for most of the time \& $4 \%$ get it for half of the time. Thus for most of the cases more than $95 \%$ of the time the information contents meet people needs using the EMR

3. $62 \%$ people believe that the system provide reports that seem to be just about exactly what they want.

4. $92 \%$ feel that the system provides sufficient information. Most of the people, around $92 \%$ believe that the system is accurate. $92 \%$ of people are satisfied with the accuracy of the system.

5. $94 \%$ respondents believe that the output is presented in a useful format and they get clear information.

6. Most $(92 \%)$ of the people feel that the system is user friendly and easy to use.

7. Almost $96 \%$ of people get the information up to date using EMR.

\section{Other findings:}

More than $90 \%$ respondents find the EMR worth the time \& effort required to use it and are satisfied with the system implemented in their departments. All the respondents feel that the performance of their department as well as their own tasks has become easier than before.

\section{V.CONCLUSION}

Thus as revealed from literature review and primary data findings, EMR has the potential to improve healthcare delivery by providing medical personnel with better data access, faster data retrieval, higher quality data and more versatility in data display. Moving the electronic medical record (EMR) into hospital and medical practice offers the potential of bringing all aspects of the patient's clinical record online. The EMR promises workflow improvements and greater efficiencies plus improved patient safety and quality of care. In addition, the greatest benefits that arise from clinical decision support and evidence based medicine are only realized when different health care providers can share information using accepted EMR standards. The electronic patient chart is also more accessible to other health practitioners who contribute to the same patient record, creating a greater sense of collaboration amongst health care workers. This is particularly relevant in a multidisciplinary practice where patients are seen by a number of practitioners.

Thus to implement EMR is a long process and hence it requires considerable attention from the management of the health care organization. However the focus should be on improvement in patient health care - technology is secondary.

\section{REFERENCES}

[1] David B. Meinert, Dane Peterson, (2009) "Perceived importance of EMR functions and physician characteristics", Journal of Systems and Information Technology, Vol. 11 Iss: 1, pp.57 - 70 https://doi.org/10.1108/13287260910932412

[2] Douglas J. Ayers, Nir Menachemi, Zo Ramamonjiarivelo, Michael Matthews, Robert G. Brooks, (2009) "Adoption of electronic medical records: the role of network effects", Journal of Product \& Brand Management, Vol. 18 Iss: 2, pp.127 - 135 https://doi.org/10.1108/10610420910949022

[3] Emerging trends in Healthcare, A journey from bench to bedside, February 17, 2011, Available: on www.kpmg.com

[4] Healthcare in India, Emerging Market Report 2007, PriceWaterHouseCoopers report from Available: on pwc.com/globalhealthcare

[5] Healthcare in India, May 30, 2012, www.oifc.in/sectors/healthcare

[6] Kurt Stanberry, (2011) "US and global efforts to expand the use of electronic health records", Records Management Journal, Vol. 21 Iss: 3, pp. $214-224$

https://doi.org/10.1108/09565691111186885

[7] Olivia F. Lee, Matthew L. Meuter, (2010) "The adoption of technology orientation in healthcare delivery: Case study of a large-scale hospital and healthcare system's electronic health record", International Journal of Pharmaceutical and Healthcare Marketing, Vol. 4 Iss: 4, pp.355 374

https://doi.org/10.1108/17506121011095209

[8] Rhonda J. Richards, Victor R. Prybutok, Sherry D. Ryan, (2012) "Electronic medical records: tools for competitive advantage", International Journal of Quality and Service Sciences, Vol. 4 Iss: 2, pp. $120-136$ https://doi.org/10.1108/17566691211232873

[9] Richard Hillestad et. Al, (2005), "Can Electronic Medical Record Systems Transform Health Care? Potential Health Benefits, Savings, And Costs", Health Aff, Vol. 24, No. 5, pp. 1103-1117 https://doi.org/10.1377/hlthaff.24.5.1103

[10] Tsipi Heart, Philip O'Reilly, David Sammon, John O'Donoghue, (2009) "Bottom-up or top-down?: A comparative analysis of electronic health record diffusion in Ireland and Israel", Journal of Systems and Information Technology, Vol. 11 Iss: 3, pp.244 - 268 https://doi.org/10.1108/13287260910983623 